\title{
PHYSICOCHEMICAL PROPERTIES OF METHACRYLATE RESIN, CALCIUM HYDROXIDE, CALCIUM SILICATE, AND SILICON-BASED ROOT CANAL SEALERS
}

\author{
Galvin Sim Siang Lin, Nik Rozainah Nik Abdul Ghani, Tahir Yusuf Noorani \\ Conservative Dentistry Unit, School of Dental Sciences, Universiti Sains Malaysia, Kubang Kerian, Kelantan, Malaysia
}

\begin{abstract}
INTRODUCTION: The use of root canal sealer, together with core filing material, is essential to provide hermetic seal in root canal system. However, different types of root canal sealer materials exhibit different properties, which may affect the quality of root canal treatment.

ОвJеCтIVEs: The aim of the study was to compare $\mathrm{pH}$, solubility, dimensional change, flow, working time, and film thickness of methacrylate resin (EndoRez), calcium hydroxide (Sealapex), calcium silicate (BioRoot RCS), and silicone-based sealer (GuttaFlow Bioseal).

MATERIAL AND METHODS: Solubility, dimensional change, flow, working time, and film thickness of root canal sealer materials were assessed based on ISO standard 6876/2012 recommendations. pH of sealer materials was measured using a pH meter. $\mathrm{pH}$, solubility and dimensional change of sealers were evaluated on day 1, 7 and 14 . Results: pH values of Sealapex, BioRoot RCS, and Guttaflow Bioseal ranged between 8.91 and 12.01, whereas EndoRez showed an average $\mathrm{pH}$ value of $6 . \mathrm{pH}$ of EndoRez increased significantly over time $(p<0.05)$, while $\mathrm{pH}$ of BioRoot RCS decreased significantly $(p<0.05)$. However, no significant $\mathrm{pH}$ change was observed in Sealapex and GuttaFlow Bioseal. BioRoot RCS showed the highest solubility $(p<0.05)$, and solubility of all sealer materials increased from day 1 to 14 , but no significant change $(p>0.05)$ was noted in BioRoot RCS and GuttaFlow Bioseal, respectively. Dimensional change of BioRoot RCS was significantly higher $(p<0.05)$, with no significant difference $(p>0.05)$ between EndoRez and Sealapex at day 1 and day 14. GuttaFlow Bioseal exhibited the highest flow value $(p<0.05)$. BioRoot RCS demonstrated the longest working time $(p<0.05)$, while EndoRez showed the lowest film thickness, which was comparable to Sealapex $(p>0.05)$.

Conclusions: EndoRez is slightly acidic, while the remaining sealer materials are alkalines. All sealers confirmed to ISO standard, except for solubility and film thickness of BioRoot RCS.
\end{abstract}

KEY WORDS: calcium hydroxide, calcium silicate, methacrylate resin, physicochemical properties, root canal sealer.

J Stoma 2021; 74, 3: 153-159

DOI: https://doi.org/10.5114/jos.2021.109181

\section{INTRODUCTION}

Root canal sealers are essential for obturation of prepared root canals to provide a three-dimensional hermetic seal, along with the use of core materials, such as gutta-percha, to prevent bacterial re-infection and root canal treatment failure [1]. Ideal properties of a root canal sealer should include excellent adhesion between a sealer and root canal wall, ability to establish a hermetic seal, no shrinkage during setting, insolubility in tissue
JOURNAL OF STOMATOLOGY CZASOPISMO STOMATOLOGICZNE
AdDress For CORRESPondence: Dr. Nik Rozainah Nik Abdul Ghani, Conservative Dentistry Unit, School of Dental Sciences, Universiti Sains Malaysia, Health Campus, 16150, Kubang Kerian, Kelantan, Malaysia, e-mail: rozainah@usm.my

ReCeIved: 15.02.2021 • ACCePted: 15.05.2021 • Published: 30.08.2021 
fluids, dimensionally stable, bio-compatibility, excellent adhesion to root canal walls, ease in handling and mixing, not resulting in tooth discoloration, antibacterial, acceptable setting time, and easy to remove during retreatment [2]. However, no existing sealer has fulfilled all the above criteria.

Currently available commercialized root canal sealers can be broadly classified according to their chemical composition, such as zinc oxide eugenol-based, calcium hydroxide-based, glass ionomer-based, epoxy resin-based, methacrylate-resin based, silicone-based, and calcium silicate-based sealers. Methacrylate resin-based sealers have been available in the market for more than 20 years, and claim to be able to bond with the root dentine walls and form a mono-block system, which improves the seal and fracture resistance of root canals of treated teeth [3]. Furthermore, they exhibit hydrophilic property, which facilitates its use in moist canals, and form resin tags into dentinal tubules [4]. To date, there are four generations of methacrylate resin-based root canal sealers, of which EndoRez is part of the second generation.

Sealapex on the other hand is a calcium hydroxide-based sealer that is bactericidal, resorbable, demonstrating good biological properties [5]. BioRoot RCS is a type of bio-ceramic-based sealer that is composed of tricalcium silicate. It has been on the market since February 2015, and comes in powder and liquid forms [6]. This sealer is indicated in case of single cone or cold lateral obturation technique used, as heat compaction would affect sealer's properties [7]. BioRoot RCS has been reported to induce angiogenic and osteogenic growth factors, exhibit low cytotoxicity, and demonstrate good adhesion to root dentine walls $[1,8]$. Subsequently, in the late 2015, GuttaFlow Bioseal was introduced, a hydrophilic silicone-based sealer that contains gutta-percha powder, polydimethylsiloxane, and bio-active glass-ceramic [9]. It is reported to demonstrate excellent alkalinizing activity, acceptable solubility, calcium release, and promising bio-activity, which stimulates tissue and bone healing $[9,10]$.

\section{OBJECTIVES}

In this context, the aim of this study was to investigate and compare various physicochemical properties, including $\mathrm{pH}$, solubility, dimensional change, flow, working time, and film thickness of EndoRez, Sealapex, BioRoot RCS, and GuttaFlow Bioseal. A null hypothesis was that there is no significant difference in the selected physicochemical properties among these four sealer materials.

\section{MATERIAL AND METHODS}

Types of root canal sealers examined in the present study and their manufacturers' details are presented in Table 1. Solubility, dimensional change, flow, working time, and film thickness of the root canal sealer materials were assessed according to ISO standard 6876:2012 recommendations [11].

\section{PH MEASUREMENT}

$\mathrm{pH}$ of sealer materials were measured according to a previously published study [12]. Sealer materials ( $n=10)$ were mixed according to manufacturers' recommendations and placed in plastic discs of $2 \mathrm{~mm}$ thickness and $10 \mathrm{~mm}$ diameter. Specimens were allowed to set for 24 hours and then immersed in small beakers containing $20 \mathrm{ml}$ of distilled water. They were placed in an incubator (ICS200; Yamato Scientific Co., Ltd., Japan) at $37^{\circ} \mathrm{C}$ for the entire experimental period. pHs were measured on day 1, 7, and 14, using a pH meter (FieldScout SoilStik; Spectrum Technologies, Inc., China), calibrated with control solution of $\mathrm{pH} 4.0$ and 7.0 at room temperature [13].

\section{SOLUBILITY TEST}

Plastic discs (1.5 mm thick and $10 \mathrm{~mm}$ diameter) were prepared and filled with each sealer material $(n=10)$. Each disc-specimen was allowed to set for 24 hours and

TABLE 1. Manufacturers' details of test materials

\begin{tabular}{|l|l|l|l|}
\hline Sealer & Mype & Manufacturer & Composition \\
\hline EndoRez & Calcium hydroxide-based & $\begin{array}{l}\text { Sybron Endo, Kerr Corporation, } \\
\text { CA, USA }\end{array}$ & $\begin{array}{l}\text { Bisthmus compound, urethane dimethacrylate (UDMA), triethylene } \\
\text { glycol dimethacrylate (TEGDMA), peroxide initiator }\end{array}$ \\
\hline Sealapex & $\begin{array}{l}\text { Base: calcium hydroxide, calcium oxide, zinc oxide, silica } \\
\text { Catalyst: bisthmus oxide, methyl salicylate, titanium dioxide, isobutyl } \\
\text { salicylate }\end{array}$ \\
\hline BioRoot RCS & Calcium silicate-based & $\begin{array}{l}\text { Septodont, Saint } \\
\text { Maur-des-Fosses, France }\end{array}$ & $\begin{array}{l}\text { Powder: tricalcium silicate, zirconium oxide, povidone } \\
\text { Liquid: calcium chloride, polycarboxylate }\end{array}$ \\
\hline GuttaFlow Bioseal & Silicon-based & $\begin{array}{l}\text { Coltene/Whaledent AG, } \\
\text { Switzerland }\end{array}$ & $\begin{array}{l}\text { Gutta-percha powder, polydimethylsiloxane, } \\
\text { platinum catalyst, zirconium dioxide, calcium salicylate, nano-silver } \\
\text { particles, bioactive glass }\end{array}$ \\
\hline
\end{tabular}


weighed using a digital balance (WN-FAN, Worner Lab, or OEM, Zhejiang, China), with an accuracy of $0.0001 \mathrm{~g}$. The mass was then recorded as $M_{1}$. Next, disc-specimens were placed into small beakers containing $20 \mathrm{ml}$ of distilled water [14], and then placed in an incubator at $37^{\circ} \mathrm{C}$, where they remained throughout the experiment. Specimens were removed on day 1,7 , and 14 . They were dried with absorbent paper and placed in a desiccator (FSD380; Tech-Lab Scientific Sdn Bhd, Malaysia) for 24 hours. Dried specimens were weighted again and recorded as $\mathrm{M}_{2}$. Measurements were repeated 3 times to obtain mean values. The solubility (SL) was determined as:

$$
\mathrm{SL}=\left(\mathrm{M}_{1}-\mathrm{M}_{2}\right) / \mathrm{M}_{1} \times 100 \%
$$

\section{DIMENSIONAL CHANGE TEST}

Each material $(n=10)$ was placed into a cylindrical silicon mould ( $6 \mathrm{~mm}$ diameter, $10 \mathrm{~mm}$ height), and were left to set for 24 hours. After setting, their surfaces were polished with a 600-grit sandpaper [14]. Height $\left(\mathrm{H}_{1}\right)$ of the sealer material was measured using a digital caliper (19975; Shinwa Rules Co., Ltd., Japan), with an accuracy of $0.01 \mathrm{~mm}$. The specimens were then stored in small beakers containing $20 \mathrm{ml}$ of distilled water, and placed in the same incubator at $37^{\circ} \mathrm{C}[12]$. On day 1,7 , and 14 , height $\left(\mathrm{H}_{2}\right)$ was re-measured. Measurements were carried out three times to obtain mean values. The dimensional change (DC) was determined as:

$$
\mathrm{DC}=\left(\mathrm{H}_{2}-\mathrm{H}_{1}\right) / \mathrm{H}_{1} \times 100 \%
$$

\section{FLOW TEST}

Each sealer material $(n=10)$ weighted $50 \mathrm{mg}$ and placed onto a glass-slide (GLP2X2; United Scientific Supplies, Inc., Waukegan, USA). Specimens were left aside for 180 seconds, followed by placement of another similar glass slide on top of sealer materials. A $100 \mathrm{~g}$ weight was placed on top of the glass slides to allow an approximate $120 \mathrm{~g}$ of weight to be exerted on sealer materials [13]. After 10 minutes, the weight was removed, and maximum and minimum diameters of the compressed sealer material were measured using a digital caliper [12]. Measurements $(\mathrm{mm})$ for each sealer were taken three times to obtain mean flow value.

\section{MEASUREMENT OF WORKING TIME}

Working time was measured according to a previous study [15]. $50 \mathrm{mg}$ of a mixed sealer was placed on a glass-slide, and left aside for three minutes. Subsequently, a second glass-slide together with a $100 \mathrm{~g}$ weight were placed on top of the sealer material. Maximum and minimum diameters of the compressed sealer material were evaluated using a digital caliper, after 10 minutes from the start of mixing. The procedure was repeated with newly mixed sealer material at increasing 30 -second interval from the beginning of mixing, until the specimen's diameter reduced by $10 \%$ of flow value. Three measurements (minutes) were taken for each sealer to obtain mean value.

\section{MEASUREMENT OF FILM THICKNESS}

Mixed sealers were placed between two glass-slides, and a $2 \mathrm{~kg}$ load (abs-sl-weight-set-small; PCS Instruments, United Kingdom) was applied on top of the glass plate to ensure equal distribution of the sealer material. After 10 minutes from the beginning of mixing, the thickness of the combined glass plates and sealer was measured with a digital caliper. Three measurements were performed for each sealer. Difference in thickness $(\mu \mathrm{m})$ between two glass-slides with and without the sealer was used to determine film thickness [15].

\section{STATISTICAL ANALYSIS}

Statistical analysis was performed using SPSS, version 24.0 for Windows 10.0 (IBM SPSS, New York, USA). Statistical significance level was set at 0.05 . Since the data violated normality test according to ShapiroWilk test, non-parametric Kruskal-Wallis test was used to evaluate the groups.

\section{RESULTS}

Based on the results showed in Table 2, the $\mathrm{pH}$ values of Sealapex, BioRoot RCS, and GuttaFlow Bioseal indicated alkalinity, with $\mathrm{pH}$ values ranging between 8.91 and 12.01, while EndoRez revealed slight acidity, with average $\mathrm{pH}$ of 6 (Figure 1A). The $\mathrm{pH}$ value of EndoRez increased significantly over 14 days $(p<0.05)$, whereas the $\mathrm{pH}$ value of BioRoot RCS decreased significantly $(p<0.05)$ from day 1 to day 14 . However, no significant $\mathrm{pH}$ changes were noted in Sealapex and GuttaFlow Bioseal throughout the time of the study. In general, BioRoot RCS demonstrated the highest solubility $(p<0.05)$, followed by GuttaFlow Bioseal, Sealapex, and EndoRez (Figure 1B). The solubility of all the sealer materials increased from day 1 to day 14 , but no significant change $(p>0.05)$ was observed in the solubility of BioRoot RCS and GuttaFlow Bioseal from day 7 to day 14, respectively.

Furthermore, the dimensional change of BioRoot RCS was significantly higher $(p<0.05)$ than the other sealer materials at all experimental periods, while EndoRez showed the least amount of dimensional change $(p<0.05)$. The dimensional change of all sealers increased from day 1 to day $14(p<0.05)$. Nonetheless, no significant difference $(p>0.05)$ in terms of a dimensional change was observed between EndoRez and Sealapex on day 1 and day 14, respectively (Figure 1C). 


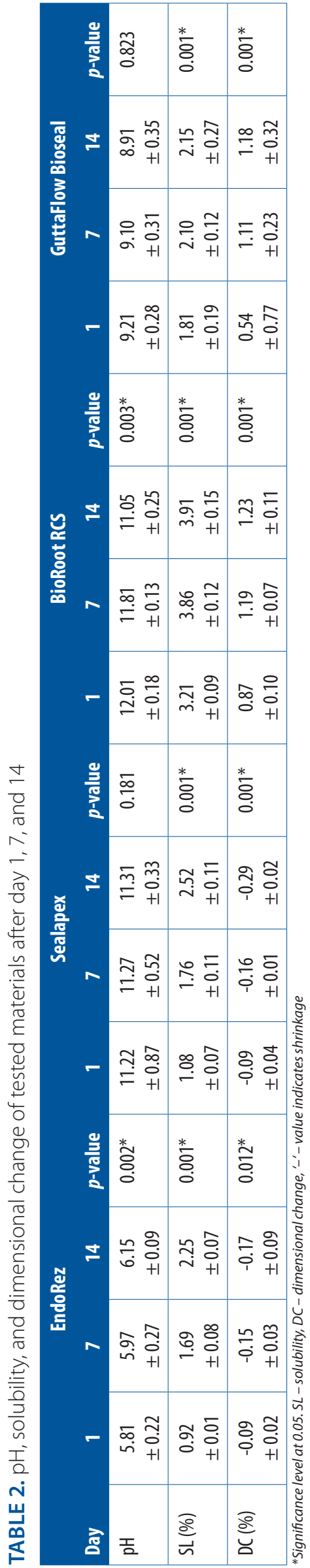

As presented in Table 3, Sealapex exhibited the lowest flow value $(p<0.05)$, followed by BioRoot RCS, EndoRez, and GuttaFlow Bioseal. Moreover, the working time of BioRoot RCS was also significantly longer than that of other sealer materials $(p<0.05)$, followed by GuttaFlow Bioseal, EndoRez, and Sealapex. EndoRez showed the lowest film thickness among all the sealer materials, but no significant differences $(p>0.05)$ were observed compared to Sealapex (Figure 1D).

\section{DISCUSSION}

The current study evaluated and compared the physicochemical properties of four different root canal sealers. Based on the results, the null hypothesis was partially rejected. In the present study, Sealapex, BioRoot RCS, and GuttaFlow Bioseal exhibited higher alkalinity $(\mathrm{pH}>7)$, which is in accordance with previously published similar studies $[6,9,16,17]$. High alkalinities of these sealer materials can be attributed to their increased hydroxyl ions dissociation upon contact with water, producing anti-microbial effect, which can lead to a decrease in the number of pathogenic root canal bacteria, such as Enterococcus faecalis [18]. In addition, the alkaline property of root canal sealers can promote hard tissue formation in the apical root region, which support better periapical healing with apatite nucleation $[6,19]$. Root canal sealers that show high alkalinity have also been reported to prevent osteoclast activity via molecular mechanisms that may accelerate periapical tissue healing [20].

The solubility of an ideal root canal sealer should not exceed $3 \%$ of their initial total mass $[11,14]$. However, only BioRoot RCS in the current study was found to violate this recommendation, with a solubility value ranging from $3.01 \%$ to $3.91 \%$, which is in agreement with other studies $[6,21]$. Although EndoRez was found to exhibit the lowest solubility value, which contradicts with results of a previous research [22], the solubility rate of EndoRez in the current study was observed to increase drastically, and one can speculate that the solubility of EndoRez would continue to rise, even after 14 days. Water solubility of each sealer material was tested because the authors believed that there is a strong correlation between sealer solubility and sealing ability [23]. A better sealing ability of root canal sealer may be related to its lower solubility. Nevertheless, a previous in-vitro study has reported that BioRoot RCS demonstrated better sealing ability of root canal [24], although it showed the highest solubility value in the current study. This could be due to different experimental setup environments, as the solubility test suggested in the available ISO specification that is inapplicable to calcium silicate-based sealers [6]. The solubility of sealer materials was evaluated by immersing them in distilled water throughout the experiment, but this did not pre- 
A

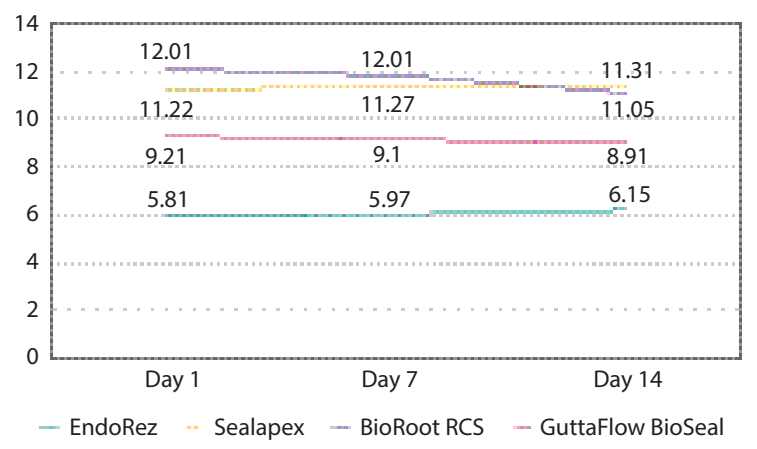

C

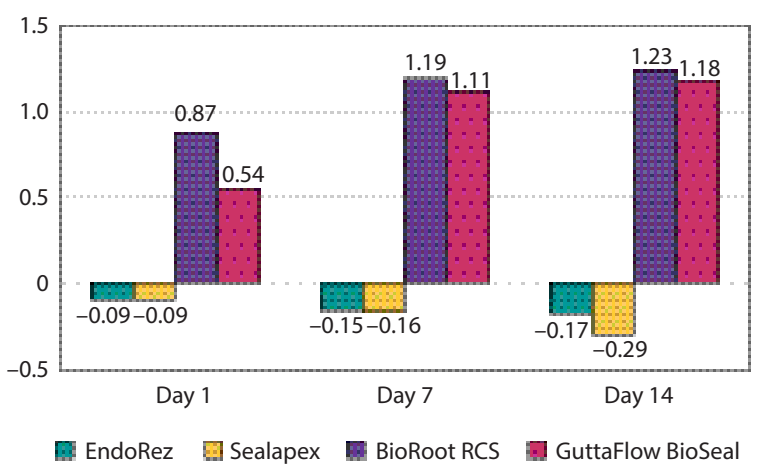

B

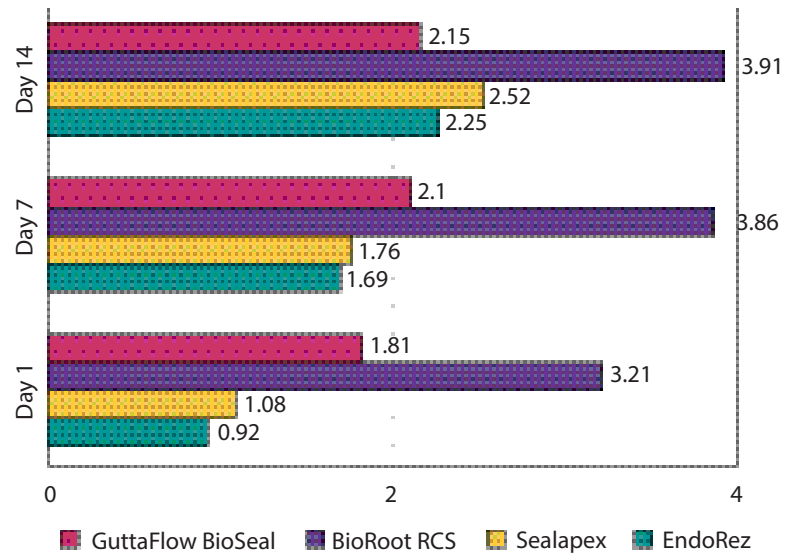

D

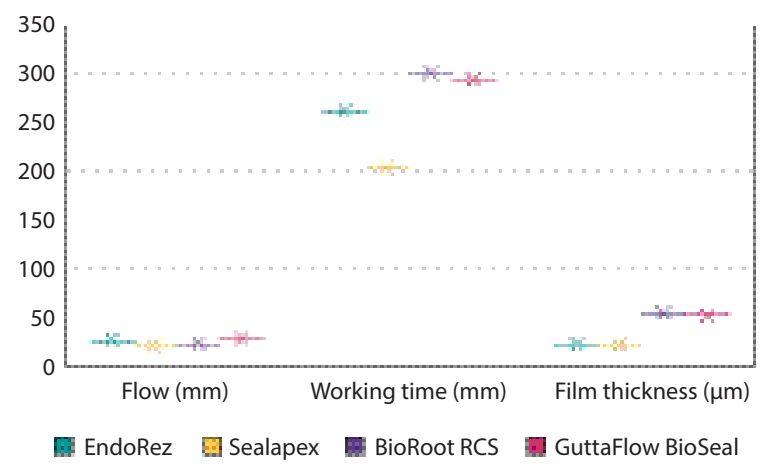

FIGURE 1. A) pH of sealer materials. B) Solubility (\%) of sealer materials. C) Dimensional change (\%) of sealer materials. D) Flow (mm), working time ( $\mathrm{min})$, and film thickness ( $\mu \mathrm{m})$ of sealer materials

TABLE 3. Flow, working time, and film thickness of tested materials

\begin{tabular}{|c|c|c|c|c|c|}
\hline & EndoRez & Sealapex & BioRoot RCS & GuttaFlow Bioseal & $p$-value \\
\hline $\mathrm{F}(\mathrm{mm})$ & $23.71 \pm 0.18$ & $18.11 \pm 0.24$ & $20.43 \pm 0.71$ & $25.73 \pm 0.41$ & $0.001^{*}$ \\
\hline WT (min) & $260.0 \pm 11.0$ & $201.0 \pm 3.0$ & $>30.0$ & $292.0 \pm 2.0$ & $0.001^{*}$ \\
\hline $\mathrm{FT}(\mu \mathrm{m})$ & $19.97 \pm 9.80$ & $20.03 \pm 8.20$ & $52.84 \pm 7.10$ & $49.93 \pm 7.7$ & $0.001^{*}$ \\
\hline
\end{tabular}

*Significance level at 0.05. F-flow, WT - working time, FT- film thickness

dict the actual situation in vivo, as root canals are dried with paper points prior to the placement of root canal sealer. Furthermore, the percolation of fluids into root canals is also prevented by a coronal restoration.

Dimensional change reveals a shrinkage or expansion of the material after setting. In this study, EndoRez and Sealapex demonstrated shrinkage, whereas BioRoot RCS and GuttaFlow Bioseal showed expansion, which is in agreement with a previous study [25]. The advantage of slight expansion of root canal sealer may contribute to better adaptation to root dentine walls and reduced micro-leakage. Nonetheless, excessive expansion is in some way unfavorable, as this may promote greater force to root dentine walls and induce dentinal cracks formation [26]. Main limitation of dimensional change test in the current study was that this method was based on a linear measurement [14]. Therefore, well-constructed and reproducible methodology, such as the use of micro-CT, should be applied to provide a three-dimensional volumetric change analysis, which allows for a better understanding and correlation of in-vitro sealer's dimensional change with clinical setting.

Flow of the sealer is important to allow the material to penetrate the canal irregularities and accessory canals for better adhesion at sealer-dentine interface [12]. In the present study, Sealapex showed significantly lower flow value $(p<0.05)$ than the other test materials, which was in line with findings of previous studies [27, 28]. All the sealer materials evaluated in the current study showed an acceptable flow (minimum $17 \mathrm{~mm}$ ) as per ISO standard [11]. However, the risk of sealer extrusion beyond the apical foramen could increase in case 
of an excessive flow [28]. Unlike BioRoot RCS and Sealapex, EndoRez and GuttaFlow Bioseal are designed as injectable sealer materials, which are susceptible to extrusion, and therefore, care should be taken by clinicians when using injectable sealer materials.

All sealer materials in the present study demonstrated acceptable and extended working time. The working time of root canal sealer mainly depends on its chemical compositions, particle size, and environment, including surrounding temperature and relative humidity [29]. Moreover, a sufficient flow within an acceptable working time is crucial for the sealer to penetrate and seal the root canal irregularities and lateral canals [15]. From a clinical perspective, an ideal root canal sealer should exhibit adequate working time, which is long enough to enable clinicians to fill the root canal. However, no standard working time for root canal sealer has been established, but an average of two hours is considered to be sufficient [30].

All the sealers in the present study, except for BioRoot RCS, presented with acceptable film thickness values $(<50 \mathrm{~mm})$ and compliance with ISO 6876:2012 specification [11]. Although BioRoot RCS has higher film thickness than that specified in ISO standard, film thickness may not be of prime interest for root canal sealer based on calcium silicate, especially when single cone obturation technique is recommended [6]. Calcium silicate-based sealers utilize their bioactivity to form a 'mineral infiltration zone' along dentine-sealer interface, and therefore, a thicker film may not compromise the sealing ability [24]. Though, a direct comparison of the present findings with other similar studies may not be feasible, probably due to different accuracies of digital caliper used.

Limitations of the current study include the period of the experiment. The $\mathrm{pH}$, solubility, and dimensional change of the examined sealer materials were only evaluated up to day 14. Therefore, longer time of observations should be implemented in future similar studies to provide more information about long-term behavior of the materials. Also, more physical testing of the sealer materials should be employed to provide better understanding and comparison of the chosen sealer materials in the current study.

\section{CONCLUSIONS}

Within the limitation of the current study, Sealapex, BioRoot RCS, and GuttaFlow Bioseal indicated alkalinity, whereas EndoRez showed slight acidity. All the examined sealers met ISO standards for solubility, dimensional change, flow, working time, and film thickness, except for BioRoot RCS, which did not fulfil specifications for solubility and film thickness. EndoRez exhibited the least solubility and comparable dimensional change with Sealapex, while GuttaFlow Bioseal demonstrated the highest flow. BioRoot RCS showed the longest working time and EndoRez demonstrated the lowest film thickness.

\section{ACKNOWLEDGEMENT}

The authors would like to thank Mr. Alvin Lee Thean Lee, Malaysia Coltene Principle, for providing GuttaFlow Bioseal sealer.

\section{CONFLICT OF INTEREST}

The authors declare no potential conflicts of interest with respect to the research, authorship, and/or publication of this article.

\section{References}

1. Lin GSS, Ghani N, Noorani TY, Ismail NH, Mamat N. Dislodgement resistance and adhesive pattern of different endodontic sealers to dentine wall after artificial ageing: an in-vitro study. Odontology 2021; 109: 149-156.

2. Wang Y, Liu S, Dong Y. In vitro study of dentinal tubule penetration and filling quality of bioceramic sealer. PLoS One 2018; 13: e0192248.

3. Tay FR, Pashley DH. Monoblocks in root canals: a hypothetical or a tangible goal. J Endod 2007; 33: 391-398.

4. Tay FR, Pashley DH. Aggressiveness of contemporary self-etching systems. I: Depth of penetration beyond dentin smear layers. Dent Mater 2001; 17: 296-308.

5. Sleder FS, Ludlow MO, Bohacek JR. Long-term sealing ability of a calcium hydroxide sealer. J Endod 1991; 17: 541-543.

6. Siboni F, Taddei P, Zamparini F, Prati C, Gandolfi MG. Properties of BioRoot RCS, a tricalcium silicate endodontic sealer modified with povidone and polycarboxylate. Int Endod J 2017; 50 Suppl 2: e120-e136.

7. Camilleri J. Sealers and warm gutta-percha obturation techniques. J Endod 2015; 41: 72-78.

8. Camps J, Jeanneau C, El Ayachi I, Laurent P, About I. Bioactivity of a calcium silicate-based endodontic cement (BioRoot RCS): interactions with human periodontal ligament cells in vitro. J Endod 2015; 41: 1469-1473.

9. Gandolfi MG, Karami Shabankare A, Zamparini F, Prati C. Properties of a novel polydimethylsiloxane endodontic sealer. G Ital Endod 2017; 31: 35-43.

10. Gandolfi MG, Siboni F, Prati C. Properties of a novel polysiloxane-guttapercha calcium silicate-bioglass-containing root canal sealer. Dent Mater 2016; 32: e113-126.

11. International Organization of Standardization. ISO 6876:2012 Dentistry - Root canal sealing materials. Geneva, Switzerland.

12. Lim ES, Park YB, Kwon YS, Shon WJ, Lee KW, Min KS. Physical properties and biocompatibility of an injectable calcium-silicate-based root canal sealer: in vitro and in vivo study. BMC Oral Health 2015; 15: 129.

13. Vertuan GC, Duarte MAH, Moraes IG, et al. Evaluation of physicochemical properties of a new root canal sealer. J Endod 2018; 44: 501-505.

14. Torres FFE, Guerreiro-Tanomaru JM, Bosso-Martelo R, Espir CG, Camilleri J, Tanomaru-Filho M. Solubility, porosity, dimensional and volumetric change of endodontic sealers. Braz Dent J 2019; 30: 368-373.

15. Zhou HM, Shen Y, Zheng W, Li L, Zheng YF, Haapasalo M. Physical properties of 5 root canal sealers. J Endod 2013; 39: 12811286 . 
16. Canadas PS, Berastegui E, Gaton-Hernandez P, Silva LA, Leite GA, Silva RS. Physicochemical properties and interfacial adaptation of root canal sealers. Braz Dent J 2014; 25: 435-441.

17. Reszka P, Kucharski Ł, Klimowicz A, Lipski M. Właściwości alkalizujące wybranych krzemianowo-wapniowych uszczelniaczy kanałowych. Badanie in vitro. Pomeranian Journal of Life Sciences $2018 ; 64$.

18. Stuart CH, Schwartz SA, Beeson TJ, Owatz CB. Enterococcus faecalis: its role in root canal treatment failure and current concepts in retreatment. J Endod 2006; 32: 93-98.

19. Tagger M, Tagger E. Periapical reactions to calcium hydroxidecontaining sealers and AH 26 in monkeys. Endod Dent Traumatol 1989; 5: 139-146.

20. Rodrigues C, Costa-Rodrigues J, Capelas JA, Fernandes MH. Longterm dose- and time-dependent effects of endodontic sealers in human in vitro osteoclastogenesis. J Endod 2013; 39: 833-838.

21. Poggio C, Dagna A, Ceci M, Meravini MV, Colombo M, Pietrocola G. Solubility and $\mathrm{pH}$ of bioceramic root canal sealers: a comparative study. J Clin Exp Dent 2017; 9: e1189-e1194.

22. Donnelly A, Sword J, Nishitani Y, et al. Water sorption and solubility of methacrylate resin-based root canal sealers. J Endod 2007; 33: 990-994.

23. Espir CG, Guerreiro-Tanomaru JM, Spin-Neto R, Chavez-Andrade GM, Berbert FL, Tanomaru-Filho M. Solubility and bacterial sealing ability of MTA and root-end filling materials. J Appl Oral Sci 2016; 24: 121-125.

24. Lin GSS, Ghani NRNA, Noorani T, Kamarudin A. Apical sealing ability of different endodontic sealers using glucose penetration test: a standardized methodological approach. Cumhuriyet Dent J 2020; 23: 79-87.

25. Camargo RV, Silva-Sousa YTC, Rosa R, et al. Evaluation of the physicochemical properties of silicone- and epoxy resin-based root canal sealers. Braz Oral Res 2017; 31: e72.

26. Islam I, Chng HK, Yap AU. Comparison of the physical and mechanical properties of MTA and portland cement. J Endod 2006 32: 193-197.

27. Torres FFE, Guerreiro-Tanomaru JM, Pinto JC, Bonetti-Filho I, Tanomaru-Filho M. Evaluation of flow and filling of root canal sealers using different methodologies. Rev Odontol UNESP 2019; 48: e20190112.

28. Tanomaru-Filho M, Bosso R, Viapiana R, Guerreiro-Tanomaru JM. Radiopacity and flow of different endodontic sealers. Acta Odontol Latinoam 2013; 26: 121-125.

29. McMichen FR, Pearson G, Rahbaran S, Gulabivala K. A comparative study of selected physical properties of five root-canal sealers. Int Endod J 2003; 36: 629-635.

30. Grossman LI. Physical properties of root canal cements. J Endod 1976; 2: 166-175. 